\title{
COVID-19 in Children with Cancer and Continuation of Cancer-Directed Therapy During the Infection
}

\author{
Badira Cheriyalinkal Parambil ${ }^{1}$. Nirmalya Roy Moulik ${ }^{1}$ Chetan Dhamne ${ }^{1} \cdot$ Nidhi Dhariwal $^{1} \cdot$ Gaurav Narula $^{1}$. \\ Tushar Vora $^{1}$ - Maya Prasad ${ }^{1}$ - Akanksha Chichra ${ }^{1}$. Shalini Jatia ${ }^{1} \cdot$ Girish Chinnaswamy $^{1}$ - Shripad Banavali ${ }^{1}$
}

Received: 26 March 2021 / Accepted: 7 June 2021 / Published online: 11 August 2021

(c) Dr. K C Chaudhuri Foundation 2021

\begin{abstract}
Objective To report the experience with COVID-19 in children with cancer at the largest tertiary-cancer care and referral center in India.

Methods This study is a single tertiary center experience on COVID-19 in children with cancer and continuation of cancerdirected therapy in them. Children $\leq 15 \mathrm{y}$ on active cancer treatment detected with COVID-19 until September $15^{\text {th }}, 2020$ were prospectively followed up in the study. Patients were managed in accordance with well-laid guidelines. Treatment was continued for children with COVID-19 who were clinically stable and on intensive treatment for various childhood cancers. Results One hundred twenty-two children (median age $8 \mathrm{y}$; range 1-15 y, male:female 1.7:1) with cancer were diagnosed with COVID-19. Of 118 children, 99 (83.9\%), 60 (50.8\%), 43 (36.4\%), 26 (22.0\%), and 6 (5.1\%) had RT-PCR positivity at $14,21,28,35$, and $60 \mathrm{~d}$ from diagnosis of COVID-19, respectively. Scheduled risk-directed intravenous chemotherapy was delivered in 70 (90.9\%) of 77 children on active systemic treatment with a median delay of $14 \mathrm{~d}$ (range $0-48 \mathrm{~d}$ ) and no increased toxicities. All-cause mortality rate was 7.4\% $(n=9)$ and COVID-19 related mortality rate was $4.9 \%(n=6)$. One hundred-fifteen (94.2\%) children with COVID-19 did not require any form of respiratory support during the course of infection.

Conclusions COVID-19 was not a major deterrent for the continuation of active cancer treatment despite persistent RT-PCR positivity. The long-term assessment of treatment adaptations requires further prospective follow-up and real-time addressal.
\end{abstract}

Keywords Cancer-directed therapy $\cdot$ Children with cancer $\cdot$ COVID-19 $\cdot$ Mortality

\section{Introduction}

The pandemic caused by severe acute respiratory syndrome coronavirus-2 (SARS-CoV-2), that causes coronavirus disease 2019 (COVID-19), has brought on an unprecedented challenge to medical care and potentially has far-reaching effects on children with cancer. Various aspects of cancer care including timely diagnosis and delivery of multimodality treatment have suffered a tremendous setback, especially in the resource-limited setting, the short- and long-term effects of which are yet to be quantified.

Girish Chinnaswamy

girish.c.tmh@gmail.com

Department of Pediatric Oncology, Tata Memorial Hospital, Homi Bhabha National Institute (HBNI), Mumbai, Maharashtra 400012, India
A higher all-cause mortality (13\%-28\%) during the pandemic has been reported in adults with cancer on active systemic therapy [1, 2]. COVID-19 in children with cancer did not lead to higher mortality in small cohorts reported earlier during pandemic [3-6]. However, the strategy of continuing intensive treatment in these children during ongoing COVID-19 infection has evolved and has not been studied systematically. In a 155-country survey in May 2020, 42\% of countries have partially or completely disrupted cancer services, which is likely to affect the outcomes of most childhood cancers, where timely diagnosis and treatment are of paramount importance [7]. The authors herein report their experience with COVID-19 in children with cancer at the largest tertiary-cancer care and referral center in India. 


\section{Material and Methods}

The pediatric oncology department at the authors' institute sees more than 2000 new registrations a year. As part of a proactive approach taken by the authors' hospital early on in the pandemic, patients were managed in accordance with well-laid guidelines and standard operating procedures (SOP) $[8,9]$. SARS-CoV-2 infection was detected by reverse-transcriptase-polymerase-chainreaction (RT-PCR) assay done on nasopharyngeal sample in every patient. Testing in children were limited to three indications: symptomatic (fever \pm other symptoms), preoperative/preprocedural (except bone marrow, lumbar puncture), high-risk contacts on day 10 of quarantine. Parents/caregivers of children with COVID were tested at the time of de-isolating the patient following a negative test or earlier, if symptomatic. All children with positive swabs were managed as inpatients in the COVID-isolation ward in anticipation of unexpected complications during the initial weeks of the pandemic and in later months given the option of isolation at home or at their accommodation facility, if stable and asymptomatic. A repeat sample to test conversion to RT-PCR negativity was initially being done within a week but later changed to $14 \mathrm{~d}$ and repeated every $5^{\text {th }} \mathrm{d}$ if positive, till negative. All children $\leq 15 \mathrm{y}$ on active cancer treatment (chemotherapy, surgery, or radiotherapy) detected to have COVID-19 until September $15^{\text {th }}, 2020$ were included and prospectively followed for $2 \mathrm{wk}$ after RT-PCR negativity was attained or till October $5^{\text {th }}, 2020$ if not yet attained. The all-cause mortality was defined as death due to any cause during the study period. COVID19-related mortality was defined as that attributed to the infection or its complication before RT-PCR negativity or immediately thereafter, if adjudged to be due to COVID19 as opposed to other causes. The time to RT-PCR negativity was calculated from the date of positivity to the date of first negative swab, with cases that had active COVID19 infection at the time of analysis censored at the last follow-up. Data were extracted from the electronic medical records, excel datasheets maintained by the department, and hospital COVID-19 database, after approval from the institutional ethics committee.

Treatment was continued for children with COVID-19 on intensive treatment for various childhood cancers if they were clinically stable, $1 \mathrm{wk}$ from RT-PCR positivity and asymptomatic for $3 \mathrm{~d}$. For children with acute leukemias where intravenous chemotherapy could not be delivered, an interim course of oral chemotherapy was initiated $[10,11]$. The treatment of children without COVID-19 was adapted to continue therapy with modifications, where interventions which had very minimal benefit, but significant toxicity necessitating frequent hospital visits were omitted or modified as detailed in an earlier report, best designed to balance cancer cure and pandemic control $[10,11]$. Similarly, routine clinical visits were curtailed to prevent overcrowding with interim blood reports, where deemed necessary communicated over telephone or email. There were outpatient clinics operational in the accommodation centers to restrict footfall in the hospital and off-treatment follow-up consults scheduled over video-conferencing platforms in these times. A day-care dedicated to the administration of intravenous chemotherapy was set up for children, who were diagnosed with COVID, in isolation at home or accommodation center, and for those asymptomatic or in quarantine, to avoid interruptions in chemotherapy.

Conventional descriptive statistics was used to analyze the data. Kaplan-Meier analysis was used to identify risk factors predictive of time to PCR negativity using log-rank test. Chi-square test for association was used to test the association between the risk factors. Multivariate analysis was performed with SPSS software using binary logistic regression. Variables tending to be significantly affecting time to RT-PCR negativity were included as independent variables in the model. The $p<0.05$ was considered significant.

\section{Results}

One hundred twenty-two children (median age $8 \mathrm{y}$; range 1-15 y, male:female 1.7:1) with cancer were diagnosed with COVID-19 during the period. Eighty-four (68.9\%) children with COVID-19 had hematological malignancies and 38 (31.1\%) had solid tumors (Tables 1 and 2).

Lymphopenia [absolute lymphocyte count $\left.(\mathrm{ALC}) \leq 1.0 \times 10^{9} / 1\right]$ at the time of positive COVID19 test was seen in 77 (64.7\%) of 119 children on active treatment whose values were available, and neutropenia with $\leq 1.0 \times 10^{9} / 1$ and $\leq 0.5 \times 10^{9} / 1$ absolute neutrophil count (ANC) were seen in 40 (33.6\%) and 32 (26.9\%) children, respectively (Table 3 ).

One hundred-fifteen (94.2\%) children with COVID19 did not require any form of respiratory support during the course of infection (Table 4). Only 7 (5.7\%) received antiviral therapy for COVID-19 (remdesivir - 5, lopinavir + ritonavir - 1 , hydroxychloroquine + azithromycin - 1). Immunomodulatory treatment was administered in 8 (6.6\%) children (dexamethasone - 5, methylprednisolone - 2, tocilizumab - 1). Three children received low-molecular weight heparin for $5 \mathrm{~d}$ in this cohort.

The median time from date of first RT-PCR positivity to first negative sample in the evaluable children with COVID-19 (excluding death - 2, defaulted before $14 \mathrm{~d}-2$ ) was $21 \mathrm{~d}$ (range 5-90 d). Of 118 children, 99 (83.9\%), 60 (50.8\%), 43 (36.4\%), 26 (22.0\%), 6 (5.1\%) had RT-PCR positivity at $14,21,28,35,60 \mathrm{~d}$ from diagnosis of COVID-19, respectively. Time to RT-PCR negativity 
Table 1 Demographic and clinical characteristics of children with COVID-19
Demographic or clinical characteristics $(n=122)$

Number of patients $n(\%)$

\begin{tabular}{|c|c|}
\hline \multicolumn{2}{|l|}{ Age } \\
\hline$\leq 5 \mathrm{y}$ & $46(37.7)$ \\
\hline $6-9 y$ & $22(18.0)$ \\
\hline$\geq 10 y$ & $54(44.3)$ \\
\hline \multicolumn{2}{|l|}{ Gender } \\
\hline Male & $77(63.1)$ \\
\hline Female & $45(36.9)$ \\
\hline \multicolumn{2}{|l|}{ Intent of treatment of cancer } \\
\hline Curative & $115(94.3)$ \\
\hline Palliative & $7(5.7)$ \\
\hline $\begin{array}{l}\mathrm{H} / \mathrm{o} \text { steroids in previous } 2 \mathrm{wk}\left(10 \mathrm{mg} / \mathrm{m}^{2} / \mathrm{d} \text { for } \geq 5 \mathrm{~d} \text { of dexamethasone or equivalent }\right. \\
\text { doses of other steroid) }\end{array}$ & $58(47.5)$ \\
\hline \multicolumn{2}{|l|}{ Reason for testing } \\
\hline Symptomatic & $100(82.0)$ \\
\hline Contact history & $10(8.2)$ \\
\hline Preprocedure & $12(9.8)$ \\
\hline \multicolumn{2}{|l|}{ Presenting clinical symptoms $(n=100)$} \\
\hline Fever & $100(100.0)$ \\
\hline Cough & $1(1.0)$ \\
\hline Breathlessness & $1(1.0)$ \\
\hline Coryza & $1(1.0)$ \\
\hline Sore throat & $2(2.0)$ \\
\hline Vomiting & $1(1.0)$ \\
\hline Headache & $1(1.0)$ \\
\hline \multicolumn{2}{|l|}{ Complications due to COVID-19 infection } \\
\hline COVID Pneumonia & $5(4.1)$ \\
\hline $\begin{array}{l}\text { Pediatric inflammatory multisystem syndrome-temporally associated with } \\
\text { SARS-CoV2(PIMS-TS) or multisystem inflammatory syndrome in children } \\
\text { (MIS-C) }\end{array}$ & 0 \\
\hline Thrombosis & 0 \\
\hline Cardiac complications & $3(2.5)$ \\
\hline Hemophagocytic Lympho-histiocytosis & $1(0.8)$ \\
\hline \multicolumn{2}{|l|}{ Associated infections and complications } \\
\hline Bacterial sepsis & $3(2.5)$ \\
\hline Ventilator-associated pneumonia & $2(1.6)$ \\
\hline Parvo viremia (existing even prior to COVID-19 diagnosis) & $1(0.8)$ \\
\hline Fungal pneumonia & $1(0.8)$ \\
\hline PJP, RSV pneumonia & $1(0.8)$ \\
\hline Miliary Tuberculosis & $1(0.8)$ \\
\hline
\end{tabular}

PJP Pneumocystis jirovecii pneumonia; RSV Respiratory syncitial virus
$(<21 \mathrm{~d}$ vs. $\geq 21 \mathrm{~d})$ was significantly associated with nadir ANC (OR 1.51, 95\% CI 1.13-2.02, $p=0.006$ ) during the course of COVID-19 infection and showed a trend with ALC-nadir during the course of infection (OR 1.63, 95\% CI $0.99-2.70, p=0.057$ ) on univariate analysis. The variables of age $(p=0.80)$, gender $(p=0.22)$, presence of symptoms $(p=0.26)$, recent steroid intake $(p=0.71)$, type of malignancy (hematological versus solid tumors, $p=0.20$ ), ANC at admission $(p=0.45)$, ALC at admission $(p=0.70)$ did not affect the time to RT-PCR negativity on univariate analysis. On multivariate analysis which included ANC and ALC during admission and nadir ANC and ALC during the course of infection, both ANC at admission (OR $0.65,95 \%$ CI $0.44-0.96, p=0.03$ ) and ANC-nadir during the course of infection (OR 2.20, 95\% CI 1.29-3.73, $p=0.004)$ affected time to RT-PCR negativity. Higher $\mathrm{ANC}$ at admission and lower ANC-nadir values were associated with delay in RT-PCR negativity. 
Table 2 Underlying malignancies in children with COVID-19

\begin{tabular}{|c|c|}
\hline Malignancy & $n(\%)$ \\
\hline \multicolumn{2}{|l|}{ Hematolymphoid } \\
\hline \multicolumn{2}{|l|}{ Leukemias } \\
\hline B cell-Acute lymphoblastic leukemia & $42(34.4)$ \\
\hline Standard risk & 6 \\
\hline Intermediate risk & 9 \\
\hline High risk & 27 \\
\hline T cell-Acute lymphoblastic leukemia & $15(12.3)$ \\
\hline Relapsed acute lymphoblastic leukemia & $8(6.6)$ \\
\hline Acute myeloid leukemia & $6(4.9)$ \\
\hline Mixed phenotypic acute leukemia (relapse-1) & $2(1.6)$ \\
\hline Chronic myeloid leukemia in blast crisis & $1(0.8)$ \\
\hline Relapsed acute promyelocytic leukemia & $1(0.8)$ \\
\hline \multicolumn{2}{|l|}{ Lymphomas } \\
\hline T-lymphoblastic lymphoma & $2(1.6)$ \\
\hline Burkitt lymphoma & $3(2.5)$ \\
\hline Anaplastic large cell lymphoma (relapse-1) & $5(4.1)$ \\
\hline \multicolumn{2}{|l|}{ Solid } \\
\hline Osteosarcoma (relapse-1) & $8(6.6)$ \\
\hline Ewing sarcoma & $6(4.9)$ \\
\hline Giant cell tumor & $1(0.8)$ \\
\hline Undifferentiated sarcoma & $2(1.6)$ \\
\hline Rhabdomyosarcoma & $2(1.6)$ \\
\hline Neuroblastoma & $2(1.6)$ \\
\hline Hepatoblastoma & $3(2.5)$ \\
\hline Wilm tumor & $3(2.5)$ \\
\hline CCSK & $1(0.8)$ \\
\hline Embryonal sarcoma of liver & $1(0.8)$ \\
\hline Relapsed retinoblastoma (CNS relapse) & $1(0.8)$ \\
\hline Germ cell tumor & $1(0.8)$ \\
\hline Low-grade glioma & $3(2.5)$ \\
\hline Ependymoma & $1(0.8)$ \\
\hline Pineoblastoma & $1(0.8)$ \\
\hline Medulloblastoma & $1(0.8)$ \\
\hline Nasopharyngeal carcinoma & $1(0.8)$ \\
\hline
\end{tabular}

At the time of analysis, 105 children had recovered and were alive, 4 had active infection (defined as SARS-CoV-2 RT-PCR positive, with/without symptoms), 9 died (6 with active infection, 3 after recovery), 2 developed reinfection and had recovered, 2 had defaulted before recovery.

All-cause mortality rate was $7.4 \%(n=9)$ with death due to progressive disease in 3. COVID-19-related mortality rate was $4.9 \%(n=6)$. COVID-pneumonia with severe ARDS was the cause of death in $4(3.3 \%, 2$ children also had ventilator-associated pneumonia, 1 child had klebsiella sepsis). Cardiac abnormalities were seen in 3 of these expired patients (decreased ejection fraction - 2, myocarditis with raised troponin - 1). Two children (1.6\%) died post attainment of RT-PCR negativity. One of them presented $11 \mathrm{~d}$ after a negative RT-PCR test with sudden-onset status epilepticus, cardiac dysfunction with acute renal and liver failure and died within $12 \mathrm{~h}$ of admission. Her cranial imaging could not be done due to rapid progression of events. The second patient had fever even after attainment of RT-PCR negativity and developed pancytopenia post RT-PCR negativity with hemophagocytic lymphohistiocytosis (HLH). He was treated with dexamethasone, etoposide, and cyclosporine but succumbed to refractory HLH.

One of the 2 children with reinfection had undifferentiated pelvic sarcoma on chemotherapy, developed fever with repeat RT-PCR positivity for SARS-CoV-2, 1.5 mo after recovery from initial COVID-19, and attained RT-PCR negativity in $32 \mathrm{~d}$ during reinfection. The other child with high-risk B-cell ALL on delayed-intensification phase developed fever with repeat positive test $26 \mathrm{~d}$ after recovery and recovered in $15 \mathrm{~d}$. Both children had not received any antiviral treatment at first infection, had only fever at reinfection and were stable.

The scheduled risk-directed intravenous chemotherapy was delivered in 70 (90.9\%) of 77 children on active systemic treatment with a median delay of $14 \mathrm{~d}$ (range $0-48$ d) and no increased toxicities. This included 7 children on induction therapy for ALL, in whom chemotherapy was continued as per schedule in 4 . There was a delay of $2 \mathrm{wk}$ in starting consolidation in 3 patients who were near completion of induction at the time of COVID-19 diagnosis, due to delay in bone marrow studies and low counts. This cohort also included 14 patients on high-dose methotrexate infusion chemotherapy who received it at a median delay of 24 d (range 6-48 d). These children received oral 6-MP in the
Table 3 Laboratory characteristics of children with COVID-19

\begin{tabular}{ll}
\hline Characteristics & Median (range) \\
\hline Absolute lymphocyte count at start of infection $\left(\times 10^{9} / \mathrm{L}\right)$ & $0.66(0.002-7.50)$ \\
Absolute neutrophil count at start of infection $\left(\times 10^{9} / \mathrm{L}\right)$ & $1.18(0.01-17.50)$ \\
Nadir absolute lymphocyte count during infection $\left(\times 10^{9} / \mathrm{L}\right)$ & $0.55(0.0002-3.83)$ \\
Nadir absolute neutrophil count during infection $\left(\times 10^{9} / \mathrm{L}\right)$ & $0.63(0.0002-11.83)$ \\
Serum ferritin levels $(\mathrm{ng} / \mathrm{mL})(n=17$ patients $)$ & $2590(136-63,340)$ \\
CRP levels $(\mathrm{mg} / \mathrm{dL})(n=19$ patients $)$ & $3.41(0.03-31.7)$ \\
D-dimer levels $(n=23$ patients $)$ & $540(228-24,605)$ \\
\hline
\end{tabular}


Table 4 Children with COVID-19 who received respiratory support

\begin{tabular}{|c|c|c|c|c|c|c|}
\hline Diagnosis & Age (y) & Phase of treatment & $\begin{array}{l}\text { Type of respiratory } \\
\text { support }\end{array}$ & $\begin{array}{l}\text { Drugs } \\
\text { (COVID directed) }\end{array}$ & $\begin{array}{l}\text { Associated compli- } \\
\text { cations }\end{array}$ & Outcome \\
\hline CML-BC & 16 & $\begin{array}{l}\text { Palliative oral } \\
\text { therapy }\end{array}$ & $\mathrm{O}_{2}$ via face mask & Nil & Leukostasis & Alive \\
\hline $\begin{array}{l}\text { Relapsed retinoblas- } \\
\text { toma }\end{array}$ & 4 & Palliation & $\mathrm{O}_{2}$ via face mask & Nil & Nil & Dead (due to disease) \\
\hline B-ALL (high-risk) & 1 & $\begin{array}{l}\text { Delayed intensifica- } \\
\text { tion }\end{array}$ & $\begin{array}{l}\text { Mechanical ventila- } \\
\text { tion }\end{array}$ & Dexamethasone & $\begin{array}{l}\text { VAP, Cardiac dys- } \\
\text { function }\end{array}$ & Dead \\
\hline Relapsed B-ALL & 12 & Palliation & $\mathrm{O}_{2}$ via face mask & Nil & $\begin{array}{l}\text { Pseudomonas sepsis, } \\
\text { Fungal pneumonia }\end{array}$ & Dead (due to disease) \\
\hline CCSK & 3 & $\begin{array}{l}\text { Adjuvant chemo- } \\
\text { therapy }\end{array}$ & $\begin{array}{l}\text { Mechanical ventila- } \\
\text { tion }\end{array}$ & Methylprednisolone & $\begin{array}{l}\text { VAP, myocarditis, } \\
\text { RSV pneumonia }\end{array}$ & Dead \\
\hline AML & 15 & $\begin{array}{l}\text { Consolidation } \\
\text { chemotherapy }\end{array}$ & $\begin{array}{l}\text { Mechanical ventila- } \\
\text { tion }\end{array}$ & Dexamethasone & $\begin{array}{l}\text { Klebsiella sepsis, } \\
\text { NEC }\end{array}$ & Dead \\
\hline Relapsed MPAL & 7 & $\begin{array}{l}\text { Palliative oral } \\
\text { therapy }\end{array}$ & $\mathrm{O}_{2}$ via face mask & $\begin{array}{l}\text { Dexamethasone, } \\
\text { remdesivir, } \\
\text { LMWH }\end{array}$ & Nil & Dead \\
\hline
\end{tabular}

$A M L$ Acute myeloid leukemia; $B$-ALL B cell acute lymphoblastic leukemia; $C C S K$ Clear cell sarcoma of kidney; $C M L-B C$ Chronic myeloid leukemia-blast crisis; $L M W H$ Low molecular weight heparin; $M P A L$ Mixed phenotypic acute leukemia; NEC Necrotizing enterocolitis; $R S V$ Respiratory syncytial virus; VAP Ventilator-associated pneumonia

interim. There were 5 children with ALL in whom maintenance chemotherapy was started or continued without delay. Intravenous chemotherapy was delivered in 19 children with solid tumors with a median delay of $12 \mathrm{~d}$ (range 3-35 d). The remaining 25 of 70 included mainly children with ALL on consolidation, interim maintenance and delayed intensification phases, and children with lymphomas. Of the 7 children who did not receive the planned intravenous chemotherapy, oral metronomic chemotherapy was started in 2 children with acute myeloid leukemia, interim oral chemotherapy was started in a child with early relapsed acute lymphoblastic leukemia (postinduction having developed hepatic candidiasis during salvage induction), autologous stem-cell transplantation was cancelled in a patient with high-risk neuroblastoma, chemotherapy was deferred in a child with stable low-grade glioma, last cycle of chemotherapy was abandoned in a child with osteosarcoma (good histological necrosis) due to COVID-19, and one child defaulted after discharge from hospital. Both the children with reinfection also received their scheduled chemotherapy without delay and adverse reactions.

Planned surgery was delayed in 9 children due to COVID-19; of which, 2 (recurrent adrenocortical carcinoma - 1, germ-cell tumor - 1) defaulted, interim cycles of intravenous chemotherapy were given in 2 till recovery (operated later), and rest were operated once recovered from infection. Two patients with brain tumors (ependymoma - 1, pineoblastoma - 1) had delay of $28 \mathrm{~d}$ in delivery of radiotherapy.

\section{Discussion}

The limited earlier data on outcomes of COVID-19 in children with cancer show no increased vulnerability to COVID-19 or associated morbidity/mortality when compared with normal children $[4,5,12]$. The reasons for decreased incidence and milder infection in children remains elusive [13, 14] and in Mumbai as of October $12^{\text {th }}, 2020,12,602$ of total 231,070 confirmed COVID-19 cases $(5.4 \%)$ and 44 of total 9,466 deaths $(0.46 \%)$ were in $<20$ y of age [15]. The cohort of children with COVID19 reported from Europe, including 25 children who were on or received chemotherapy in the previous 6 mo also showed a favorable outcome of COVID-19, with a casefatality rate of $0.69 \%$ [3]. The authors herein describe the largest cohort of children with cancer from a single center on active treatment (chemotherapy, surgery and or radiotherapy) with $82.7 \%$ on intravenous chemotherapy and another $9.0 \%$ having received it in the last 3 mo. COVID-19-related mortality in the present cohort (4.9\%) is relatively higher than reports from China and Europe, which had showed rates less than $1 \%$ in children $(<19 \mathrm{y})$ and that of the otherwise healthy children $(<20 \mathrm{y})$ from Mumbai $(0.46 \%)[3,4,15,16]$, which may be attributed to the higher incidence of bacterial infections in the present cohort where 4 of the 6 children dying of COVIDpneumonia had superadded bacterial VAP and sepsis. However, the COVID-related mortality rate is similar to that reported in a review of 226 pediatric cancer patients 
with COVID from various countries [17]. Nevertheless, they warrant close follow-up during the course of infection and shortly thereafter. A sizeable proportion (23\%) of patients in the aforementioned review were managed at home, and therefore, patients who are non-neutropenic, asymptomatic/mildly symptomatic, and not on intensive chemotherapy are best managed as outpatients with a system for regular technology-based follow-up and early flagging of warning signs [18].

In a descriptive study from Wuhan comprising all ages, the median period from symptoms onset to negative SARSCoV-2 RT-PCR test result was $20 \mathrm{~d}$ [17]. Though the median time to RT-PCR negativity was $21 \mathrm{~d}$ in the present cohort, one-half and one-fifth of the children had RT-PCR positivity at 3 wk and 5 wk of diagnosis of COVID-19, respectively. Higher ANC at admission and lower ANC-nadir during the course of infection were associated with delay in attainment of RT-PCR negativity. This may be partly due to the fact that those children with higher ANC at admission would have received the scheduled intensive systemic chemotherapy. This could have contributed to lower nadir-ANC and immunosuppression, which coupled with the immunosuppression due to cancer seemed to have played a role in the delayed clearance of virus as evidenced by the increased time taken to attain negativity in $50.8 \%$ of the children with COVID-19 and symptomatic reinfection in two of them. The reinfections in the present cohort were so adjudged as they were symptomatic at second episode, had a significant time elapsed since primary infection that had documented clearance, and were reconfirmed on RT-PCR with lower cycle threshold values compared to the last negative report. However, a limitation is that this could not be validated by simultaneous viral cultures.

Immunosuppression in children with cancer on active treatment is a concern for serious complications with COVID-19, and the present study showed slightly increased mortality in this selected population compared to previous reports. As reported by previous studies [17], majority of the infected children were only mildly symptomatic and stable, and COVID-19 positivity was not a major deterrent to the continuation of planned active therapy with or without modifications. A systematic review has reported delay in planned chemotherapy in nearly three quarters of the patients [17]. The initial paucity of information and resultant uncertainties in the understanding of this new pandemic did cause some delay in the treatment in the present cohort of children in the early phase, which was offset by timely execution of planned SOPs and guidelines.

For pragmatic delivery of cancer care, a strategy with following goals was evolved at the authors' institute early into the pandemic: to maintain low inpatient and daycare burden, to maintain low-resource utilization while not compromising on the curative intent and expected survivals $[9-11,19]$. The steps in this direction helped in the care of patients with and without COVID-19. The outcomes of treatment deferrals and modifications will need to be measured over time.

While screening for COVID-19, though guidelines issued by the government and national advisory bodies were followed, there is a selection bias in the study in that only those who were symptomatic or had a high-risk contact were tested, vis-à-vis universal testing of all patients with cancer. This together with false-negative RT-PCR test results, could have underestimated the true incidence. In contrast, a New York study had showed no increased incidence when asymptomatic children with cancer were screened for COVID-19 [5]. Only a few required ICU admissions or received antiviral, immunomodulatory treatment in this cohort, which limits any further conclusions regarding severe infection and COVID-19 directed therapy. Despite these limitations, this represents a comprehensive review of a large single-center cohort of children with cancer on active treatment diagnosed with COVID-19 and provides compelling grounds for uninterrupted cancer-directed treatment in this population.

\section{Conclusions}

In the present cohort of children with cancer, COVID-19 was not a major deterrent to the continuation of active cancer treatment despite persistent positivity, and occasional reinfection. The long-term assessment of treatment adaptations requires further prospective follow-up and real-time addressal.

Acknowledgements The team would like to acknowledge Drs Shyam Srinivasan, Radnyi Mande, Venkata Rama Mohan Gollamudi, Megha Saroha, Subramaniam Ramanathan, Anuj Singh, Juhi Shah, Swaminathan K, Anisha Panda, Vignesh Subramani, Swetha V, and Amit Kumar for the help provided in data collection and managing COVID-isolation wards and other patient services during these times. The authors would also like to acknowledge all staff in Tata Memorial Hospital for the relentless efforts and also Ms Smruti Mokal, for the help in the statistical analysis.

Authors' Contribution BCP conceptualized and designed the study, designed the data collection instruments, coordinated and supervised data collection, carried out the initial analyses, drafted the initial manuscript, and reviewed and revised the manuscript. NRM, CD conceptualized and designed the study, designed the data collection instruments, supervised data collection, and reviewed and revised the manuscript. GN, TV, MP, AC, GC, SB conceptualized and designed the study, and critically reviewed the manuscript for important intellectual content. ND collected the data, and helped in drafting the manuscript. SJ helped in data collection and analysis and reviewed and revised the manuscript. All authors approved the final manuscript as submitted and agree to be accountable for all aspects of the work. GC will act as the guarantor for this paper.

Data Availability Upon reasonable request. 


\section{Declarations}

Ethics Approval This study was performed in line with the principles of the Declaration of Helsinki. Approval was granted by the Ethics Committee of University B (Final approval on18.06.2020/ NoIEC/0620/3480/001)

Consent to Participate Verbal informed consent taken from the parents.

Consent for Publication No identifying information in the article.

Conflict of Interest None.

\section{References}

1. Kuderer NM, Choueiri TK, Shah DP, et al. Clinical impact of COVID-19 on patients with cancer (CCC19): a cohort study. Lancet. 2020;395:1907-18.

2. Lee LY, Cazier JB, Angelis V, et al. COVID-19 mortality in patients with cancer on chemotherapy or other anticancer treatments: a prospective cohort study. In: Europe PMC. Available at: https://europepmc.org/article/med/32473682. Accessed on 19 July 2020.

3. Götzinger F, Santiago-García B, Noguera-Julián A, et al. COVID19 in children and adolescents in Europe: a multinational, multicentre cohort study. Lancet Child Adolesc Health. 2020;4:653-61.

4. Hrusak O, Kalina T, Wolf J, et al. Flash survey on severe acute respiratory syndrome coronavirus- 2 infections in paediatric patients on anticancer treatment. Eur J Cancer. 2020;132:11-6.

5. Boulad F, Kamboj M, Bouvier N, Mauguen A, Kung AL. COVID19 in children with cancer in New York City. JAMA Oncol. 2020;6:1459-60.

6. Radhakrishnan V, Ovett J, Rajendran A, et al. COVID19 in children with cancer in low- and middle-income countries: Experience from a cancer center in Chennai. India Pediatr Hematol Oncol. 2021;38:161-7.

7. Coronavirus (COVID-19) events as they happen. In:World Health Organization. Available at: https://www.who.int/emergencies/ diseases/novel-coron avirus-2019/events-as-they-happen. Accessed on 1 July 2020.

8. Pramesh CS, Badwe RA. Cancer management in India during Covid-19. N Engl J Med. 2020;382:e61.

9. Tata Memorial Centre COVID-19 Working Group. The COVID19 pandemic and the tata memorial centre response. Indian J Cancer. 2020;57:123.
10. Dhamne C, Vora T, Prasad M, et al. Comment on: The COVID-19 Pandemic: A rapid global response for children with cancer from SIOP, COG, SIOP-E, SIOP-PODC, IPSO, PROS, CCI and St. Jude Global.In: Pediatric Blood and Cancer.2020.Available at: https://www.researchgate.net/publication/341388868_Comment_ on_The_COVID-19_Pandemic_A_rapid_global_response_for_ children_with_cancer_from_SIOP_COG_SIOP-E_SIOP-PODC IPSO_PROS_CCI_and_St_Jude_Global. Accessed on 1 July 2020.

11. Saroha M, Moulik NR.COPING with CORONA: A developing country perspective on managing children with cancer during COVID-19 pandemic.In: Cancer Res Stat Treat.2020.Available at: http://www.crstonline.com/article.asp?issn=2590-3233; year= 2020; volume $=3 ;$ issue $=5 ;$ spage $=97 ;$ epage $=101 ;$ aulast $=$ Saroha . Accessed on 1 July 2020.

12. Balduzzi A, Brivio E, Rovelli A, et al. Lessons after the early management of the COVID-19 outbreak in a pediatric transplant and hemato-oncology center embedded within a COVID-19 dedicated hospital in Lombardia. Italy Estote parati Bone Marrow Transplant. 2020;55:1900-5.

13. Children may be less affected than adults by novel coronavirus (COVID-19). J Paediatr Child Health. 2020;56:657.

14. Brodin P. Why is COVID-19 so mild in children? Acta Paediatr. 2020;109:1082-3.

15. Stop Coronavirus - with Right Information \& Simple Measures : Key Updates \& Trends. 2020. Available at: https://stopcoronavirus. mcgm.gov.in/key-updates-trends. Accessed on 2 July 2020.

16. Epidemiology Working Group for NCIP Epidemic Response, Chinese Center for Disease Control and Prevention. [The epidemiological characteristics of an outbreak of 2019 novel coronavirus diseases (COVID-19) in China]. Zhonghua Liu Xing Bing Xue Za Zhi. 2020;41:145-151.

17. Meena JP, Kumar Gupta A, Tanwar P, Ram Jat K, Mohan Pandey $\mathrm{R}$, Seth R. Clinical presentations and outcomes of children with cancer and COVID-19: a systematic review. Pediatr Blood Cancer. 2021;68:e29005.

18. Xiao AT, Tong YX, Gao C, Zhu L, Zhang YJ, Zhang S. Dynamic profile of RT-PCR findings from 301 COVID-19 patients in Wuhan, China: a descriptive study. J Clin Virol. 2020;127:104346.

19. Seth R, Das G, Kaur K, et al. Delivering pediatric oncology services during a COVID-19 pandemic in India. Pediatr Blood Cancer. 2020;67:e28519.

Publisher's Note Springer Nature remains neutral with regard to jurisdictional claims in published maps and institutional affiliations. 